\title{
Photogrammetry and Laser Imagery Tests for Tank Waste Volume Estimates: Summary Report
}

Author Name:

J. G. Field

Washington River Protection Solution, LLC

Richland, WA 99352

U.S. Department of Energy Contract DE-AC27-08RV14800

$\begin{array}{lll}\text { EDT/ECN: } & \text { DRF } & \text { UC: } \\ \text { Cost Center: } & & \text { Charge Code: } \\ \text { B\&R Code: } & & \text { Total Pages: } 15\end{array}$

Key Words: Cold Test Facility, CTF, Feasibility Test, CCMS, Camera/CAD Modeling System, Photogrammetry, Laser, FARO, Technology Development,

Abstract: Feasibility tests were conducted using photogrammetry and laser technologies to estimate the volume of waste in a tank. These technologies were compared with video Camera/CAD Modeling System (CCMS) estimates; the current method used for post-retrieval waste volume estimates. This report summarizes test results and presents recommendations for further development and deployment of technologies to provide more accurate and faster waste volume estimates in support of tank retrieval and closure.

TRADEMARK DISCLAIMER. Reference herein to any specific commercial product, process, or service by trade name, trademark, manufacturer, or otherwise, does not necessarily constitute or imply its endorsement, recommendation, or favoring by the United States Government or any agency thereof or its contractors or subcontractors.

APPROVED

By G. E. Bratton at 8:02 am, Mar 27, 2013

Release Approval
Date

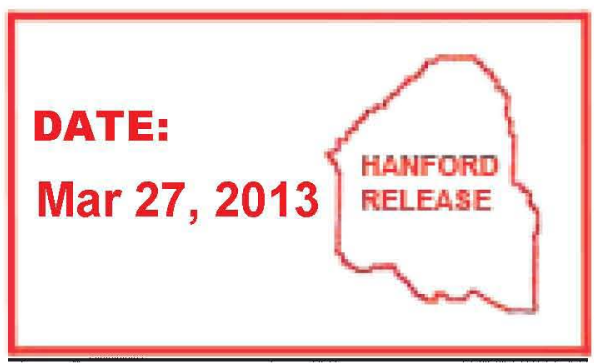

Release Stamp

\section{Approved For Public Release}


RPP-54602, Rev. 0

\section{Table of Contents}

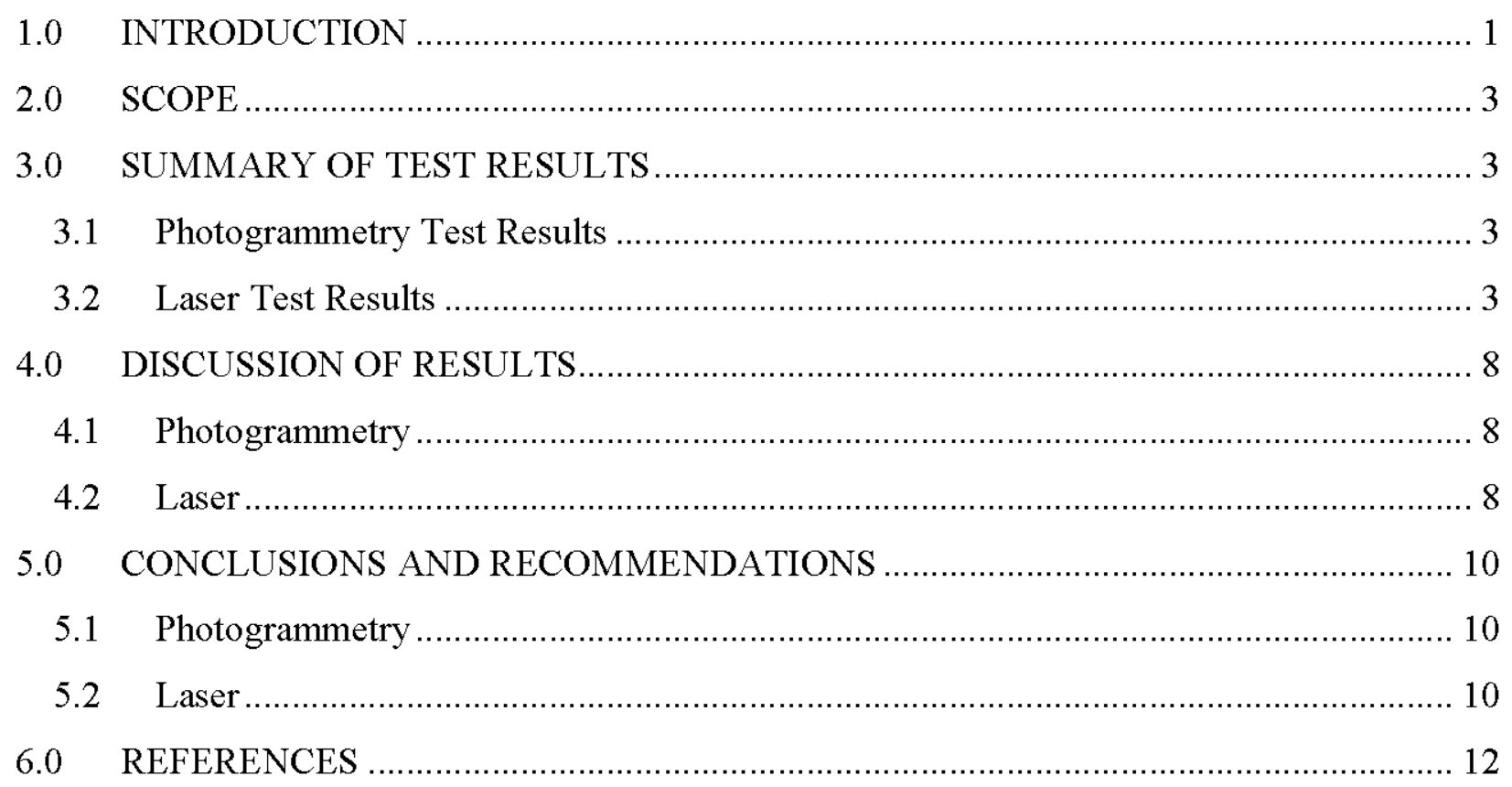




\section{INTRODUCTION}

Feasibility tests were conducted using photogrammetry and laser technologies to estimate the post-retrieval volume of waste in a tank. These technologies were compared with video Camera/CAD Modeling System (CCMS) estimates; the current method used for post-retrieval waste volume estimates. This report summarizes test results and presents recommendations for further development and deployment of technologies to provide more accurate and faster waste volume estimates in support of tank retrieval and closure.

Post-retrieval tank waste volume estimates are needed to assess retrieval performance, to determine whether a maximum of $360 \mathrm{ft}^{3}$ of waste remains in the tank to meet retrieval criteria and to estimate residual waste inventory in support of risk assessments. These results are documented initially in a retrieval completion report and ultimately in a retrieval data report provided to the Washington State Department of Ecology (Ecology) per Appendix I of the Hanford Federal Facility and Consent Order (HFFACO).

A video Camera/CAD Modeling System (CCMS) is the current approach used for post-retrieval waste volume estimates. This approach requires manual interpretation of videos obtained during

and after retrieval, sketching video content and transferring sketches to an AutoCAD ${ }^{\circledR}$ program for a final tank waste diagram and waste residual volume estimate. The CCMS method requires extensive training and time to qualify CCMS modelers, requires 2 to 3 weeks to complete an estimate for each tank and has an estimated error of $\pm 20 \%$ at a $95 \%$ confidence level (RPP23403, Single-Shell Tank Component Closure Data Quality Objectives).

Photogrammetry and laser technologies were previously reviewed at Hanford as a means of estimating tank waste residuals. It was concluded that the CCMS method provided the most reliable technology that could be applied at that time. As a result, the CCMS method has been used through 2012 to estimate post-retrieval residual waste volumes for C-100 and C-200 series tanks. Developments in photogrammetry and laser technologies and enhanced computer systems show promise of faster, more accurate results. A competitive bid contract (Requisition \#251420) was developed to conduct feasibility tests using photogrammetry and laser technologies to estimate waste volumes. The contract was awarded to HiLine Engineering and Fabrications, Inc.

Photogrammetry work was performed to determine whether more accurate and faster estimates could be obtained using currently available tank operations and test videos. One task for the photogrammetry test was to estimate the volume of 16 dirt piles in a CCMS qualification video. If successful, the photogrammetry process could be qualified for use per TFC-ENG-FACSUPCD-22, Post-Retrieval Tank Waste Volume Determinations. A second task was to estimate the volume of waste in tank C-104 using post-retrieval videos.

Laser testing was performed as a feasibility test. Laser imagery testing was conducted at the Cold Test Facility (CTF) located in North Richland. Two dirt and gravel test piles with 
measured volumes were setup inside the CTF mock single-shell tank and a FARO ${ }^{\circledR 1}$ Laser Scanner Focus ${ }^{3 \mathrm{D}} 120$ (Focus $^{3 \mathrm{D}}$ ) was used to scan the piles. Four of the five vendors that submitted proposals, proposed using the Focus ${ }^{3 \mathrm{D}}$ for the test. This was one of the few scanners identified that met the procurement requirement that the system fit down a 12 in. diameter riser. Table 1-1 shows specifications and general information for the Focus ${ }^{3 \mathrm{D}}$.

\section{Table 1-1. Specifications for the Focus ${ }^{3 \mathrm{D}}$ Laser Scanner.}

\begin{tabular}{|c|c|}
\hline $\begin{array}{l}\text { Ranging unit } \\
\text { Unambiguity interval: } 153.49 \mathrm{~m}(503.58 \mathrm{ft}) \\
\text { Range Focus }{ }^{3 \mathrm{D}} 120^{1}: 0.6 \mathrm{~m}-120 \mathrm{~m} \text { indoor or outdoor with low ambient } \\
\text { light and normal incidence to a } 90 \% \text { reflective surface. } \\
\text { Measurement speed: } 122,000 / 244,000 / 488,000 / 976,000 \text { points } / \mathrm{sec} \\
\text { Ranging error } 2: \pm 2 \mathrm{~mm} \text { at } 10 \mathrm{~m} \text { and } 25 \mathrm{~m} \text {, each at } 90 \% \text { and } 10 \%\end{array}$ & $\begin{array}{l}\text { Deflection Unit } \\
\text { Vertical field of view: } 305^{\circ} \\
\text { Horizontal field of view: } 360^{\circ} \\
\text { Vertical step size: } 0.009^{\circ}\left(40,9603 \mathrm{D} \text { pexels on } 360^{\circ}\right) \\
\text { Horizontal step size: } 0.009^{\circ}\left(40,9603 \mathrm{D} \text { pexels on } 360^{\circ}\right) \\
\text { Max. vertical scan speed: } 5,280 \mathrm{rpm} \text { or } 97 \mathrm{~Hz} \\
\end{array}$ \\
\hline $\begin{array}{l}\text { reflectivity. } \\
\text { Ranging noise }{ }^{3} \text { : } \\
@ 10 \mathrm{~m} \text { - raw data: 0.6mm @ 90\% refl. |1.2mm @10\% refl. } \\
@ 10 \mathrm{~m} \text { - noise compressed4: 0.3mm @90\% refl. | 0.6mm @10\% refl. } \\
@ 25 \mathrm{~m} \text { - raw data: 0.95m @ 90\% refl.|2.2 mm @ 10\% refl. } \\
@ 25 \mathrm{~m} \text { - noise compressed4: 0.5 mm @90\% refl. } 11.1 \mathrm{~mm} @ 10 \% \text { refl. }\end{array}$ & $\begin{array}{l}\text { Laser (Optical Transmitter) } \\
\text { Laser power (cw Ø): } 20 \mathrm{~mW} \text { (Laser class 3R) } \\
\text { Wavelength: } 905 \mathrm{~nm} \\
\text { Beam divergence: Typical } 0.16 \mathrm{mrad}\left(0.009^{\circ}\right) \\
\text { Beam diameter at exit: } 3.8 \mathrm{~mm} \text {, circular }\end{array}$ \\
\hline $\begin{array}{l}\text { Color Unit } \\
\text { Resolution: Up to } 70 \text { megapixel color } \\
\text { Dynamic color feature: Automatic adaption of brightness }\end{array}$ & $\begin{array}{l}\text { Data Handling and Control } \\
\text { Data storage: } \mathrm{SD}, \mathrm{SDHC}(\mathrm{SDX} \AA, 32 \mathrm{~GB} \text { card included } \\
\text { Scanner control: Via touch-screen display }\end{array}$ \\
\hline $\begin{array}{l}\text { General } \\
\text { Power supply voltage: } 19 \mathrm{~V} \text { (external supply), } 14.4 \mathrm{~V} \text { (internal battery) } \\
\text { Power consumption: } 40 \mathrm{~W} \text { and } 80 \mathrm{~W} \text { respectively (while battery charges) } \\
\text { Battery life: Up to } 5 \text { hours } \\
\text { Ambient temperature: } 5^{\circ} \mathrm{C}-40^{\circ} \mathrm{C} \\
\text { Humidity: Non-condensing } \\
\text { Cable connector: Located in scanner mount }\end{array}$ & $\begin{array}{l}\text { Weight: } 5.0 \mathrm{~kg} \\
\text { Size: } 240 \times 200 \times 100 \mathrm{~mm}^{3} \\
\text { Maintenance calibration: Annual } \\
\text { Parallax-free: Yes } \\
\text { Dual-axes inclination sensor: Accuracy } 0.015^{\circ} \text {, Range } \pm 5^{\circ}\end{array}$ \\
\hline
\end{tabular}

\footnotetext{
${ }^{1}$ FARO is a registered trademark of FARO Technologies Inc,
} 
RPP-54602, Rev. 0

\subsection{SCOPE}

This report summarizes test results and provides recommendations for future testing and deployment.

Testing procedures and more detailed test results are presented in RPP-RPT-54593, Using Photogrammetry to Estimate Tank Waste Volumes From Video, and RPP-RPT-54539, Cold Test Facility Tank Laser Imagery Test for Tank Volume Estimates.

\subsection{SUMMARY OF TEST RESULTS}

\subsection{Photogrammetry Test Results}

CCMS test videos and C-104 post-retrieval videos were provided to the vendor to estimate tank waste (or simulated waste) volumes using automated photogrammetry processes. The CCMS test video is described in RPP-17663, Test Plan for the Video Camera/CAD Modeling System and the C-104 post-retrieval video is described in RPP-CALC-54284, Post-Hard Heel Retrieval Camera/CAD Modeling System Waste Volume Estimate For Tank 241-C-104.

A $3 \mathrm{D}$ reconstruction of the CCMS test video using photogrammetry could not be created because of several issues with the video discussed in section 4.1.

Using the post-retrieval video for tank C-104, the photogrammetry software estimated a waste volume of $499 \mathrm{ft}^{3}$. As discussed in section 4.1, this estimate is highly uncertain.

Photogrammetry test procedures and test results are presented in more detail in RPP-RPT-54593.

\subsection{Laser Test Results}

The Focus ${ }^{3 \mathrm{D}}$ laser scanner was used to scan the dirt and gravel piles in the CTF on January 11, 2013. The piles were scanned from three locations on the CTF platform above the tank (Figure $3-1)$ using the $4 X$ quality setting on the scanner at three different levels of resolution (1:4 [10 minute scan], 1:8 [5 minute scan] and 1:16 [2 minute scan]) in the daylight (1:00 to 4:00 P.M.) and after dark ( 6:00 to 8:00 P.M.). Data taken from the TP3 location was not used in the volume calculations because 12 in. center risers are not available in single-shell tanks. The measured volume of the piles was withheld from the test contractor until after providing scanning estimates.

The estimated waste pile volumes were calculated using: 1 raw scan data, 2. polygonal mesh data and 3. 3D CAD system calculations after export from Polyworks. Methods of calculation and detailed test results are provided in RPP-RPT-54539. 
Figure 3-1. Laser Scan Locations

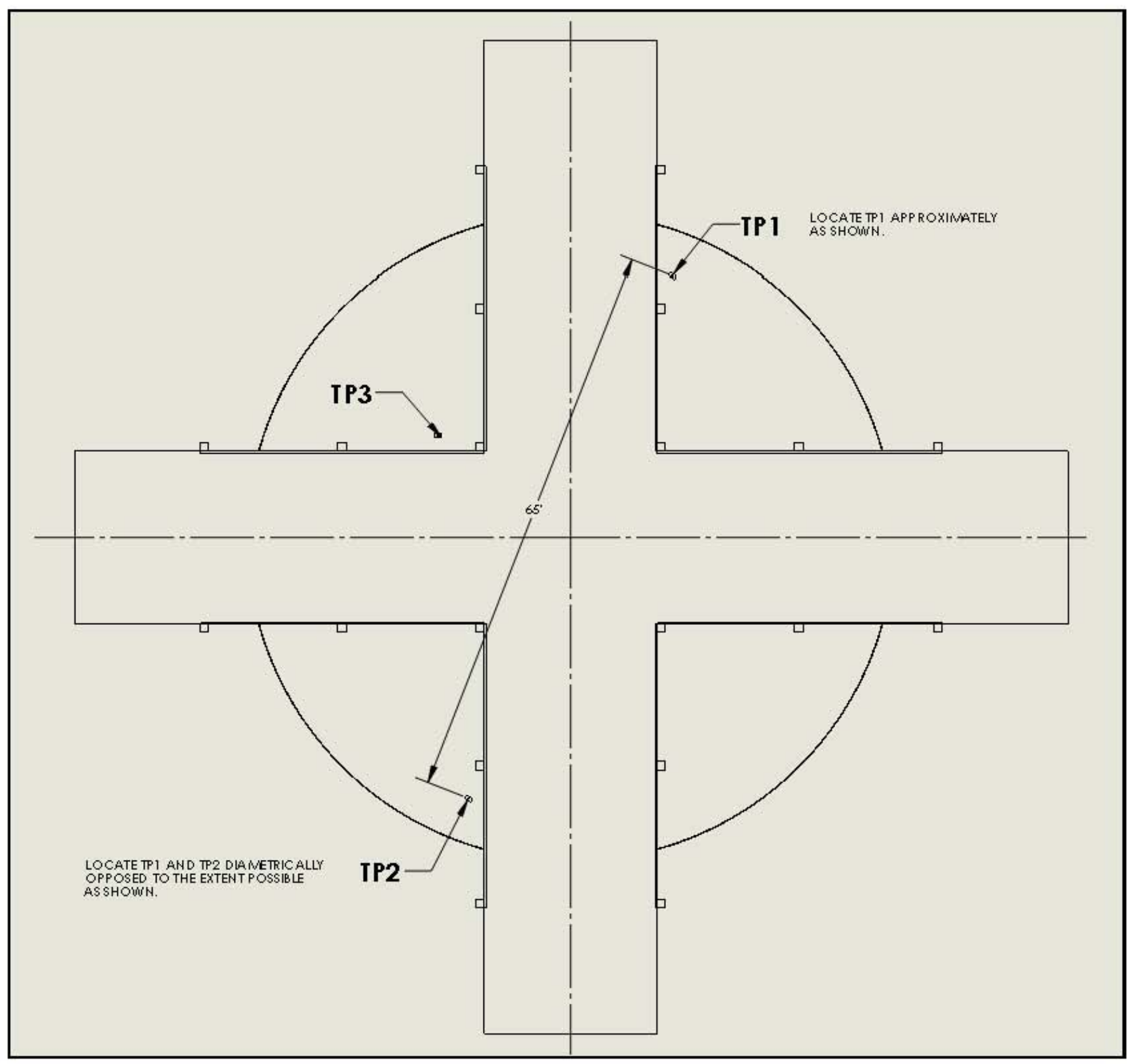

There was no perceptible difference in clarity or feature recognition between day and night scans and minimal gain using the 1:4 as compared to the 1:8 resolution scans. Figures 3-2 and 3-3 show night results for the 1:4 and 1:8 scanning resolutions from TP1. Tables 3-1 and 3-2 show night scan results for the 1:8 resolution scan, measured pile volumes, variances between scans and percent difference from measured values for waste piles 1 and 2. Table 3-3 shows combined results. Table 3-3 summarizes the total combined volume and range variance for waste piles 1 and 2 . 
RPP-54602, Rev. 0

Figure 3-2. Night Focus ${ }^{3 \mathrm{D}}$ Scan from TP1 at Resolution 1:4- 4X

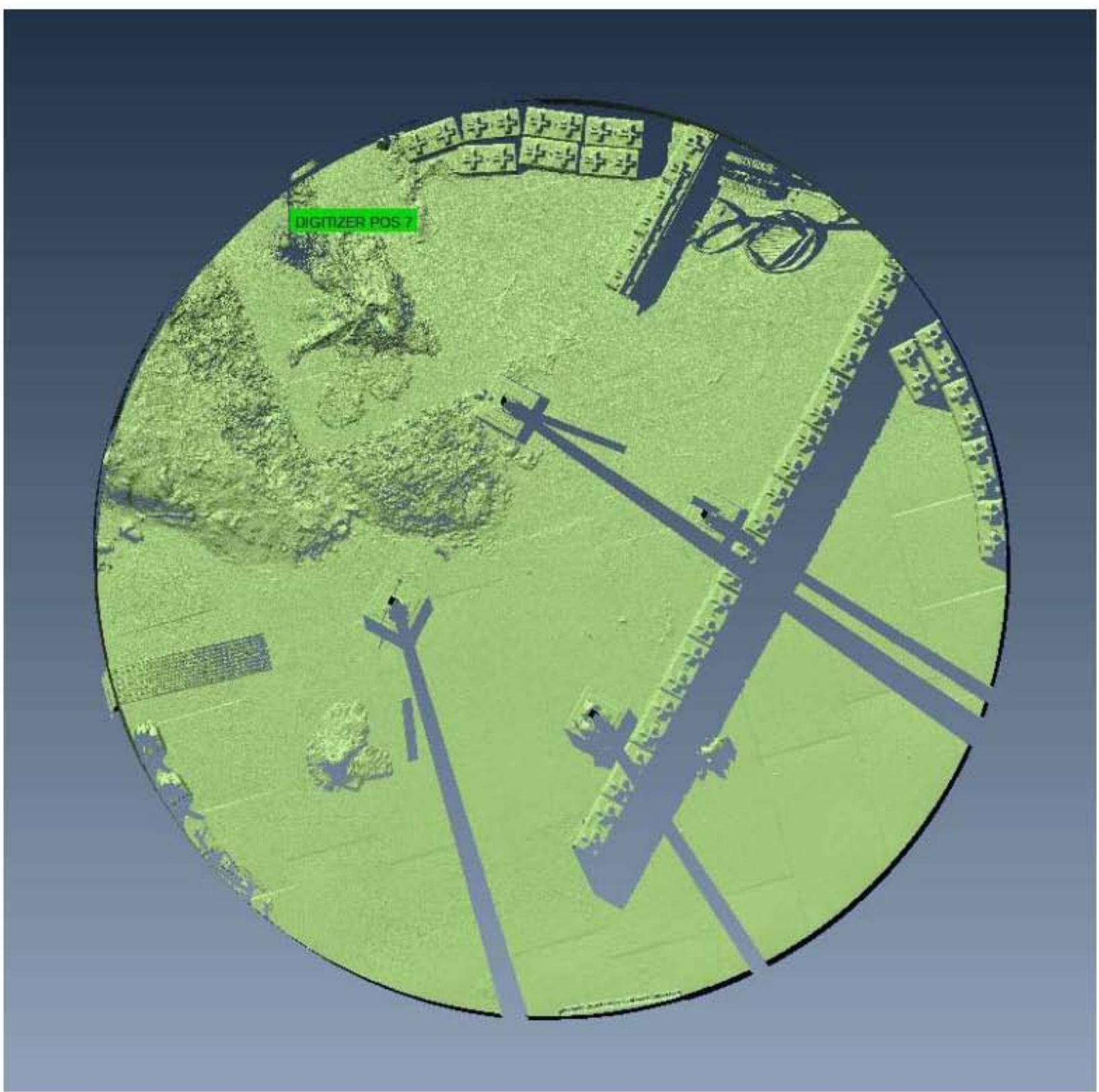


RPP-54602, Rev. 0

Figure 3-3. Night Focus ${ }^{3 \mathrm{D}}$ Scan from TP1 at Resolution 1:8- $4 \mathrm{X}$

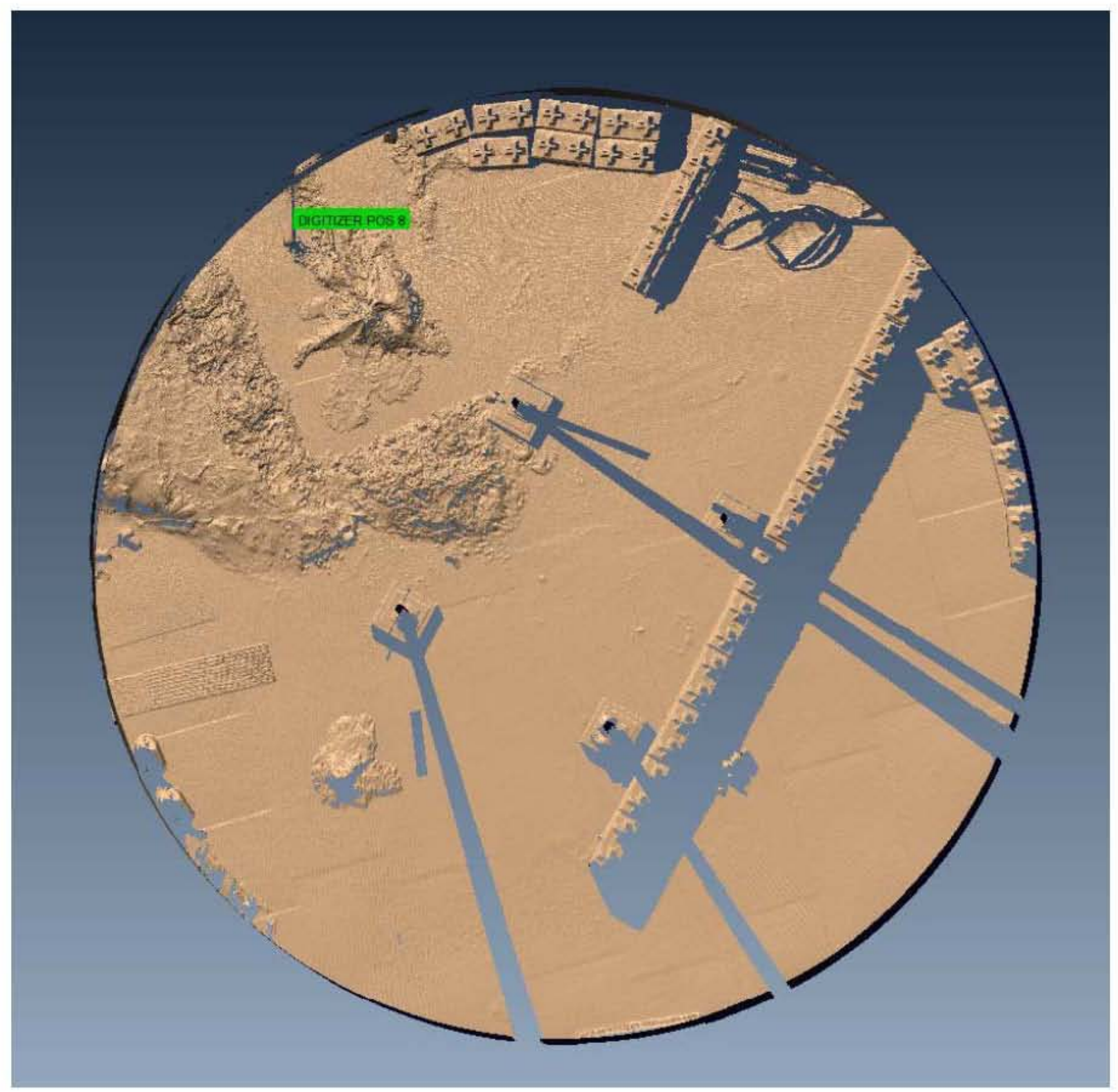


Table 3-1. Volume Estimates and Variances for Pile 1 Night Scans.

\begin{tabular}{|c|c|c|c|c|}
\hline & $\begin{array}{c}\text { Raw Scan, Night } \\
(1: 4-4 \mathrm{X}) \\
\mathrm{ft}^{3} \\
\left(\mathrm{~m}^{3}\right)\end{array}$ & $\begin{array}{c}\text { Raw Scan, Night } \\
(1: 8-4 \mathrm{X}) \\
\mathrm{ft}^{3} \\
\left(\mathrm{~m}^{3}\right)\end{array}$ & $\begin{array}{c}\text { Raw Scan, Night } \\
(1: 16-4 \mathrm{X}) \\
\mathrm{ft}^{3} \\
\left(\mathrm{~m}^{3}\right)\end{array}$ & $\begin{array}{l}\text { Max. Variance in } \\
\text { resolution } \\
\text { settings } \\
(\%)\end{array}$ \\
\hline pile1 & $\begin{array}{c}8.90 \\
(.252)\end{array}$ & $\begin{array}{c}8.86 \\
(.251)\end{array}$ & $\begin{array}{c}8.86 \\
(.251)\end{array}$ & 0.45 \\
\hline
\end{tabular}

\begin{tabular}{|c|c|c|c|c|c|c|c|}
\hline & $\begin{array}{c}\text { Raw Scan } \\
\text { Night } \\
(1: 8-4 X) \\
\mathrm{ft}^{3} \\
\left(\mathrm{~m}^{3}\right)\end{array}$ & $\begin{array}{c}\text { Mesh } \\
\text { Night } \\
(1: 8-4 \mathrm{X}) \\
\mathrm{ft}^{3} \\
\left(\mathrm{~m}^{3}\right)\end{array}$ & $\begin{array}{c}\text { CAD } \\
\text { Night } \\
(1: 8- \\
4 \mathrm{X}) \\
\mathrm{ft}^{3} \\
\left(\mathrm{~m}^{3}\right)\end{array}$ & $\begin{array}{c}\text { Measured } \\
\mathrm{ft}^{3}\end{array}$ & $\begin{array}{c}\text { Variance } \\
\text { Raw Scan } \\
\text { to } \\
\text { Measured } \\
(\%)\end{array}$ & $\begin{array}{c}\text { Variance } \\
\text { Mesh to } \\
\text { Measured } \\
(\%)\end{array}$ & $\begin{array}{c}\text { Variance } \\
\text { CAD to } \\
\text { Measured } \\
(\%)\end{array}$ \\
\hline pile1 & $\begin{array}{c}8.86 \\
(.252)\end{array}$ & $\begin{array}{c}9.15 \\
(.259)\end{array}$ & $\begin{array}{c}9.07 \\
(.257)\end{array}$ & 10.0 & 11.40 & 8.50 & 9.30 \\
\hline
\end{tabular}

Table 3-2. Volume Estimates and Variances for Pile 2 Night Scans.

\begin{tabular}{|c|c|c|c|c|c|}
\hline & $\begin{array}{c}\text { Raw } \\
\text { Scan } \\
\text { Night } \\
(1: 8-4 X) \\
\mathrm{ft}^{3} \\
\text { (cu m) }\end{array}$ & $\begin{array}{c}\text { Volume } \\
\text { Mesh } \\
\text { Night } \\
(1: 8-4 X) \\
\mathrm{ft}^{3} \\
\text { (cu m) }\end{array}$ & $\begin{array}{l}\text { Volume } \\
\text { WRPS } \\
\text { Known } \\
\text { (cu.ft.) }\end{array}$ & $\begin{array}{l}\text { Variance Raw } \\
\text { Scan to } \\
\text { Known } \\
(\%)\end{array}$ & $\begin{array}{c}\text { Variance } \\
\text { Mesh to } \\
\text { Known } \\
(\%)\end{array}$ \\
\hline waste_pile 2 & $\begin{array}{c}52.37 \\
(1.483) \\
\end{array}$ & $\begin{array}{c}48.31 \\
(1.368)\end{array}$ & 50.00 & 4.74 & 3.38 \\
\hline
\end{tabular}

Table 3-3. Combined Scan Volumes and Variances for Waste Piles 1 and 2.

\begin{tabular}{|c|c|c|c|c|c|}
\hline & $\begin{array}{c}\text { Volume } \\
\text { Raw Scan } \\
\text { Night }(1: 8- \\
4 X) \\
\text { cu ft } \\
\text { (cu m) }\end{array}$ & $\begin{array}{c}\text { Volume } \\
\text { Mesh } \\
\text { Night } \\
(1: 8-4 X) \\
\text { cu ft } \\
\text { (cu m) }\end{array}$ & $\begin{array}{l}\text { Volume } \\
\text { WRPS } \\
\text { Known } \\
\text { (cu.ft.) }\end{array}$ & $\begin{array}{c}\text { Range Variance } \\
\text { Raw Scan to } \\
\text { Known } \\
(\%)\end{array}$ & $\begin{array}{c}\text { Range } \\
\text { Variance } \\
\text { Mesh to } \\
\text { Known } \\
(\%)\end{array}$ \\
\hline waste_pile 182 & $\begin{array}{c}61.23 \\
(1.734) \\
\end{array}$ & $\begin{array}{c}57.46 \\
(1.627)\end{array}$ & 60 & 2.05 & 4.23 \\
\hline
\end{tabular}


RPP-54602, Rev. 0

\subsection{DISCUSSION OF RESULTS}

\subsection{Photogrammetry}

Industry leading photogrammetry software \& methods were used, but the software was unable to obtain enough data from the CCMS test video to reproduce video images. Consequently, volume estimates could not be determined. Several issues and recommended actions were identified to improve future video for photogrammetry, these include:

- Use a fixed zoom lens,

- Remove text overlay,

- Use soft well balanced lighting,

- Use a digital video signal to prevent diagonal interference,

- Increase feature count.

Using the post-retrieval video provided, the photogrammetry software estimated a waste volume of $499 \mathrm{ft}^{3}$ for tank C-104. This estimate is much higher than preliminary estimates of $190.9 \mathrm{ft}^{3}$ (RPP-CALC-53365, Waste Volume of Single-Shell Tank 241-C-104 Remaining after Hard Heel Retrieval) and CCMS estimates of $217 \mathrm{ft}^{3}$ (RPP-CALC-54284, Post-Hard Heel Retrieval Camera/CAD Modeling System Waste Volume Estimate For Tank 241-C-104) using the same video. The large difference from other estimates and uncertainty in the estimate as described in the test report appear to be much greater than the $20 \%$ uncertainty for CCMS tank waste volume estimates.

The photogrammetry approach utilized minimizes, but does not eliminate, the human interaction required to interpret the data \& results. While the post-retrieval video for tank C-104 was a better quality video for photogrammetry compared to the CCMS test video, many of the same issues and recommendations apply to improve results.

Key recommendations include:

- Higher resolution images,

- Digital single lens camera,

- Still image camera,

- Soft lighting.

\subsection{Laser}

The maximum volume range variance from the measured volume for waste pile 1 was $-11.4 \%$. The variance for waste pile 2 was $+4.74 \%$, with a combined variance of $+2.05 \%$. The polygonal mesh approach had the lowest variance for the individual pile sizes. All of the pile size calculation volumes were well under $20 \%$ variance, indicating that waste volume estimates using laser scanning are significantly more accurate than estimates using the CCMS approach. 
Potential sources of error in pile volumes include the accuracy of the measured volume, the quality of the scan data collected and the level of manipulation required to get to the resultant "reverse engineered" geometry.

Compaction was identified as a primary factor potentially affecting the accuracy of the known volume measurement. No amount of shaping or forming of surfaces can occur without some compaction. Compaction of pile 1 seems especially likely given that all of the scan estimates for pile 1 were low. Minor error may have also been introduced in interpreting the "exact" 5-gallon level for each bucket used. Although unquantifiable, there is likely error in the known volumes.

The Focus ${ }^{3 \mathrm{D}}$ used has been determined to be accurate to $+/-2 \mathrm{~mm}$ at 25m (+/-.080" @ 82') (See Table 1-1). To put this into perspective, if measurements for a one cubic foot volume of material are off by the entire tolerance band of $0.160^{\prime \prime}$, the measured volume would be 1.04 cubic feet resulting in a potential maximum error of $4 \%$.

The remaining source of error is related to the human element in the reverse engineering process. This is difficult to quantify as it is variable and depends on the type of object being reverse engineered. The more irregular the shapes digitized, the more human interaction is required to reasonably interpret $\&$ reduce the data. For example, one assumption for the waste piles was that the floor of the tank is flat. A datum plane was established based on randomly selecting three points located on the flat surface adjacent to the perimeter of the waste pile. This reference plane served as the datum for the volume calculations. Each step in the reverse engineering process requires a human decision such as this, which introduces potential error in the calculations.

Finally, it was observed that the results for the larger pile (pile 2) were closer to measured values than results for the small pile. It stands to reason it is easier to measure a large pile accurately, relative to a small pile. The error of all of the decisions will be amplified for the smaller pile by moving the surface during reverse engineering. For example, a $10 \%$ shift on a 1 " deep pile would be only a $1 \%$ shift on a 10 " deep pile. 
RPP-54602, Rev. 0

\subsection{CONCLUSIONS AND RECOMMENDATIONS}

Photogrammetry and laser systems were tested to assess accuracy and speed in estimating the volume of waste in a tank.

\section{$5.1 \quad$ Photogrammetry}

Photogrammetry tests were conducted to determine if an automated process could be used to obtain more accurate and faster tank waste volume estimates using post-retrieval videos currently available. The tests showed that higher quality video or still photographs are needed for the photogrammetry system tested to be successful. Given the nature and quality of the video, the photogrammetry process tested could not be fully automated.

No estimates were provided for the 16 simulated waste piles in the CCMS test qualification video and the estimate for the waste volume in tank C-104 was high, with a large range of uncertainty compared to other volume estimates (see Section 4.1).

\section{Recommendation}

Although better video and photographs could be obtained that would result in more accurate photogrammetry estimates, literature reviewed and the photogrammetry experts conducting the test suggested that laser systems would be faster and more accurate than photogrammetry. No further testing of photogrammetry systems is recommended.

\subsection{Laser}

\section{Accuracy}

Laser feasibility tests were conducted to demonstrate the accuracy of laser scanning systems. The volume estimates based on the raw scan data were low by $11.5 \%$ compared to measured volume of the small pile (pile 1 ) and high by $4.7 \%$ for the larger pile (pile 2 ). With additional data processing, the volume estimates for polygonal mesh estimates were low by $8.5 \%$ for pile 1 and high by $3.4 \%$ for pile 2 . All of these calculations are significantly more accurate than the CCMS uncertainty of $20 \%$.

\section{Speed}

In addition to being more accurate, the Focus ${ }^{3 \mathrm{D}}$ scan and data calculation is fast. The Faro ${ }^{3 \mathrm{D}}$ scan at 1:8-4X resolution, took only 4 minutes. A visual scan of the tank was available immediately, after the scan was completed. Processing is also completed quickly. The laser system scan results can be available with-in a few days. In contrast, a CCMS video estimate requires 2 to 3 hours to obtain video and 3 or 4 weeks to review the video and complete a volume estimate.

\section{Cost}

The Focus3D runs about $\$ 40,000$ plus minor set up and temporary installation costs. The initial cost is higher than for video cameras which run $\sim \$ 20,000$ each plus setup and installation. 
However, the initial cost is offset by the time and resources required to complete post-retrieval tank waste volume estimates. The CCMS method, currently used to interpret video requires 3 to 4 months to qualify a CCMS modeler $(\sim 60,000$ at $\$ 100 / \mathrm{hr})$. As noted above, it takes another 2 or 3 weeks after obtaining the CCMS video to review the video, complete a drawing and calculate waste volume $(\sim \$ 12,000)$.

Initial indications are that the laser system can be reused in multiple tanks. This would need to be further investigated, but if true could result in spreading the initial capital expense.

\section{Other Applications}

One of the sources of error in waste volume estimates is the actual configuration of the tank below the tank waste. Currently, waste volumes are estimated assuming that the configuration of the tank is as shown in tank construction drawings. However, this is not always the case. Laser range measurements for tanks C-105 and C-107 (RPP-RPT-48168, C-107 Centering Tool Data Evaluation) showed that the tank diameters were respectively 6 in and 9 in smaller than shown in construction drawings. Bulges or ripples in the tanks or deformities after 40 years of storing waste appear to have contributed to other changes in the tank configuration, as noted in differences between tank waste volume displacement and video estimates for tanks C-108 and C109 (RPP-CALC-53490, Estimated Waste Volume Remaining in Single-Shell Tank 241-C-109 After Hard Heel Retrieval). After tank waste is removed or nearly removed and only a small amount of waste remains, the digital data from laser system scans could be used to determine the actual dimensions of tanks or other structures (eg. Valve and pump pits).

Laser scanning systems could also be used before retrieval to provide better estimates of the volume of waste in tanks to be retrieved, to monitor small changes in the waste surface over time to help evaluate surface level changes, and to identify/measure tank cracks or corrosion in support of tank integrity evaluations.

\section{Recommendation}

Additional laser testing is recommended.

Initially, laser scans already obtained at CTF using the Focus ${ }^{3 \mathrm{D}}$ should be further evaluated and processed by HiLine. A supplemental contract is recommended to:

1. Reproduce the CTF drawing and compare it with construction drawings.

2. Use the scan to estimate the total volume of concrete blocks in CTF.

Once supplemental feasibility testing is completed. Testing in a single-shell tank is recommended. A Focus ${ }^{3 \mathrm{D}}$ could be purchased and HiLine could be contracted to assist in design/development work to test the Focus ${ }^{3 \mathrm{D}}$ in a single-shell tank. HiLine could also help to set-up and train WRPS personnel to operate the laser system in the tank farms to estimate waste volumes for a tank previously retrieved or for the next tank to be retrieved. Results could be compared with CCMS video estimates.

This would demonstrate application of the Focus ${ }^{3 \mathrm{D}}$ laser scanner in a radioactive environment. 
RPP-54602, Rev. 0

\subsection{REFERENCES}

RPP-CALC-53365, 2012, Waste Volume of Single-Shell Tank 241-C-104 Remaining after Hard Heel Retrieval, Rev. 0, Washington River Protection Solutions, Richland, Washington.

RPP-CALC-53490, Estimated Waste Volume Remaining in Single-Shell Tank 241-C-109 After Hard Heel Retrieval, Rev. 0, Washington River Protection Solutions, Richland, Washington.

RPP-CALC-54284, 2013, Post-Hard Heel Retrieval Camera/CAD Modeling System Waste Volume Estimate For Tank 241-C-104, Rev. 0, Washington River Protection Solutions, Richland, Washington.

RPP-RPT-48168, 2010, C-107 Centering Tool Data Evaluation, Rev. 0, Washington River Protection Solutions, LLC, Richland, Washington. 